University of Nebraska - Lincoln

DigitalCommons@University of Nebraska - Lincoln

\title{
$4-15-1988$
}

\section{Magnetic transitions and phases in random-anisotropy magnets}

David J. Sellmyer

University of Nebraska-Lincoln, dsellmyer@unl.edu

S. Nafis

University of Nebraska - Lincoln

Michael J. O'Shea

Kansas State University, mjoshea@phys.ksu.edu

Follow this and additional works at: https://digitalcommons.unl.edu/physicssellmyer

Part of the Physics Commons

Sellmyer, David J.; Nafis, S.; and O'Shea, Michael J., "Magnetic transitions and phases in randomanisotropy magnets" (1988). David Sellmyer Publications. 138.

https://digitalcommons.unl.edu/physicssellmyer/138

This Article is brought to you for free and open access by the Research Papers in Physics and Astronomy at DigitalCommons@University of Nebraska - Lincoln. It has been accepted for inclusion in David Sellmyer Publications by an authorized administrator of DigitalCommons@University of Nebraska - Lincoln. 


\title{
Magnetic properties of rapidly quenched and annealed Fe ${ }_{10} \mathrm{RTI}$ and related alloys
}

\author{
Z. R. Znao, Y. G. Ren, K. D. Aylesworth, and D. J. Sellmyer \\ Behlen Laboratory of Physics, University of Nebraska, Lincoln, Nebraska 68588-0111 \\ E. Singleton, J. Strzeszewski, and G. C. Hadjpanayis \\ Department of Physics, Kansas State University, Manhattan, Kansas 66506
}

\begin{abstract}
Magnetic measurements are reported for iron-rich ternary alloys with the following compositions: $\mathrm{Fe}_{10} \mathrm{Nd}_{x} \mathrm{Dy}_{1-x} \mathrm{Ti}(0 \leqslant x \leqslant 1), \mathrm{Fe}_{10} \mathrm{SmM}(\mathrm{M}=\mathrm{Ti}, \mathrm{V}$, and $\mathrm{Mo})$, and $\mathrm{Fe}_{10} \mathrm{RV}$ $(R=Y, G d$, and $D y)$. The samples were prepared by splat cooling or melt spinning and selected samples were heat treated. The results of $x$-ray diffraction, electron microscopy, and thermomagnetic measurements on the $\mathrm{Fe}_{10} \mathrm{Nd}_{x} \mathrm{Dy}_{1-x} \mathrm{Ti}$ series are presented and indicate that the rapidly quenched alloys are nearly single phase and become multiphase upon heating. Magnetic measurements on the other two series show that the substitution of $V$ for Ti increases the saturation magnetization.
\end{abstract}

\section{INTRODUCTION}

The search for novel permanent magnet materials has recently focused on ternary alloys containing iron, a rare earth, and a transition metal. Interest in these materials was sparked by the discovery of $\mathrm{Fe}_{14} \mathrm{Nd}_{2} \mathrm{~B}$ several years ago. Alloys of the 14:2:1 type have relatively large coercivities (though not larger than Sm-Co based magnets) and large energy products.

Recently Ohashi et al. ${ }^{2}$ discovered another iron-rich compound, $\mathrm{Fe}_{10} \mathrm{SmTi}$, with an anisotropic structure. Their results indicate that single-phase alloys with this 10:1:1 stoichiometry can only be produced with heavy rare earths. If a light rare earth is used the alloy becomes a phase mixture of the 10:1:1 phase with $\alpha-\mathrm{Fe}$ and $\mathrm{Fe}_{2} \mathrm{R}$, or $\mathrm{Fe}_{3} \mathrm{R}$.

In this work we investigate the use of rapid-quenching techniques in the production of single-phase 10:1:1 alloys, and the possibility that these techniques could be used to stabilize single-phase alloys containing light rare earths. In addition, the effects of substituting $V$ and $M o$ for $T i$ were studied.

\section{EXPERIMENTAL METHODS}

Rapidly quenched samples of $\mathrm{Fe}_{10} \mathrm{Nd}_{x} \mathrm{Dy}_{1 \ldots x} \mathrm{Ti}$ $(x=0.0,0.33,0.60,1.0), \mathrm{Fe}_{10} \mathrm{SmM}(\mathrm{M}=\mathrm{Ti}, \mathrm{V}$, and $\mathrm{Mo})$, and $\mathrm{Fe}_{10} \mathrm{RV}(\mathrm{R}=\mathrm{Y}, \mathrm{Gd}$, and $\mathrm{Dy})$ were prepared by splatcooling or melt-spinning mixtures containing the appropriate weight of each element.

Measurements were made on the rapidly quenched alloys and selected samples were subjected to a heat treatment at $800^{\circ} \mathrm{C}$ for $1 \mathrm{~h}$ in a pure argon atmosphere.

The crystal structure of the $\mathrm{Fe}_{10} \mathrm{Nd}_{x} \mathrm{Dy}_{1 \ldots x} \mathrm{Ti}$ series was investigated by $\mathrm{CuKa} \mathrm{x}$-ray diffraction and by electron microscopy with a transmission-electron microscope (TEM), and thermomagnetic data on this series were obtained with a high-temperature vibrating-sample magnetometer (VSM). The moment of each sample was measured in a constant $1.3-\mathrm{kOe}$ field while the temperature was slowly raised to $650^{\circ} \mathrm{C}$, held constant for $20 \mathrm{~min}$, and then slowiy lowered to room temperature.

This VSM was also used to obtain room-temperature hysteresis loops to $8 \mathrm{kOe}$ for each series. Some additional measurements to $80 \mathrm{kOe} \mathrm{at} 100 \mathrm{~K}$ were made in a low-temperature VSM.

\section{IIL. RESULTS AND DISCUSSION}

Representative resuits of the $x$-ray diffraction, electron microscopy, and thermomagnetic measurements for the $\mathrm{Fe}_{k 0} \mathrm{Nd}_{x} \mathrm{Dy}_{1-x}$ Ti series are shown in Figs. 1, 2, and 3, respectively. The top half of Fig. 1 shows $x$-ray diffraction data for an as-quenched sample with $x=0.0$. All of the lines can be indexed according to the tetragonal structure proposed by Ohasin $e t a l .^{2}$ However, electron diffraction patierns (Fig. 2 ) in several grains of an annealed $\mathrm{Fe}_{10}$ Dy $\mathrm{T}$ i sample are inconsistent with this structure; rather, they are generally consistent with a $\mathrm{ThMn}_{12}$ structure with $c=4.8 \AA, a=8.3$ $\AA(c / a=0.58)$. The x-ray data can also be indexed successfully with this latter structure. In addition, Fig. 2(b) shows satellites that suggest a structural modulation along the $c$

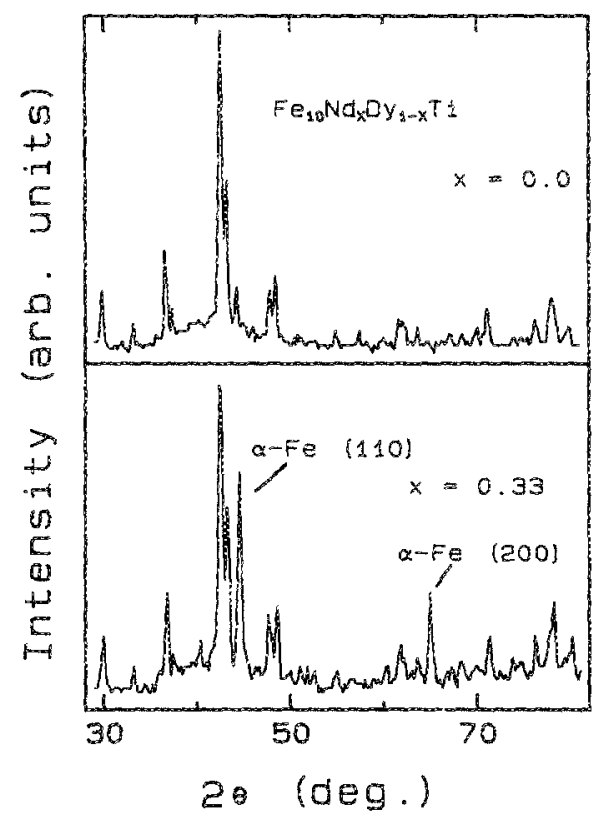

FIG. 1. X-ray diffruction patterns for $x=0.0$ and 0.33 ( $\mathrm{CuK \alpha} \alpha$ radiation). 


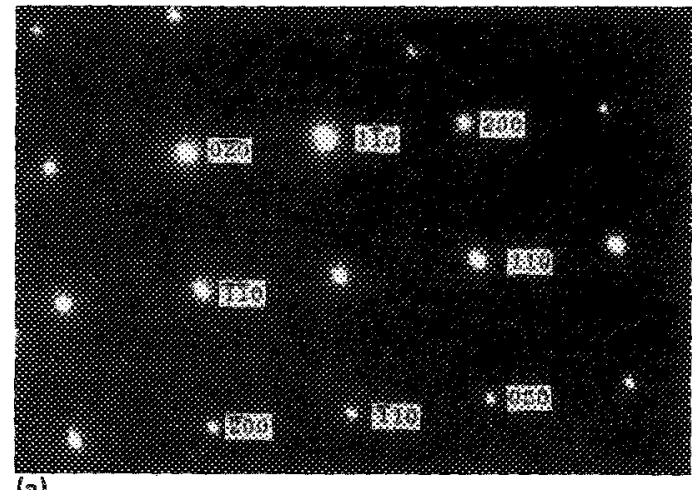

(a)

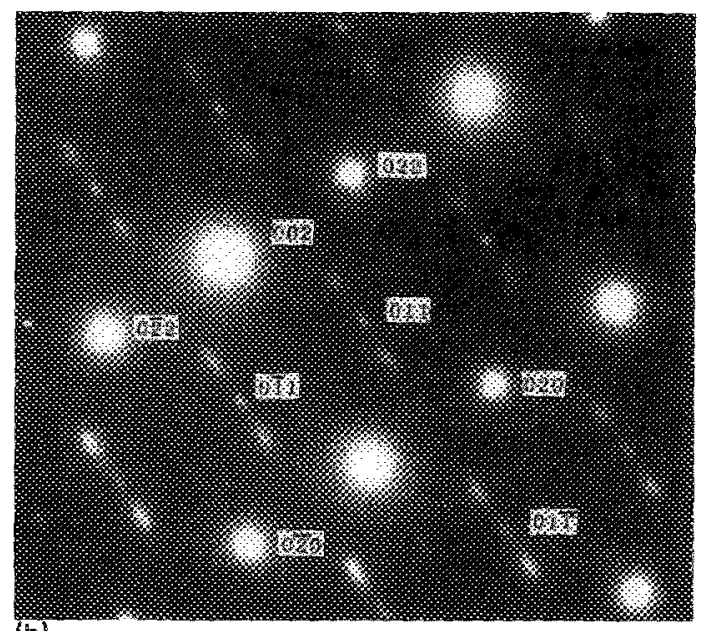

(b)

FR. 2. Electron difraction data for heat-treated $\mathrm{Fe}_{10}$ DyTi. (a) shows fourfold retation symmetry about $[00 \overline{1}]$. In $(b)$ the bean is along [100], and a modulation of about $12 \AA$ along the $c$ direction is seen.

axis with a period of about $12 \AA$. Thus, it is possible that the rapidly quenched material has a relatively simple tetragonal structure and that annealing produces a rather complex structure. Further work is necessary to determine whether the as-quenched material also has this structural modulation.

The absence of $\alpha$-Fe peaks in the $x$-ray pattern for $x=0.0$ indicate that the sample is single phase in the asquenched state. Preliminary $x$-ray data (not presented here) for as-quenched $\mathrm{Fe}_{10} \mathrm{NdT}$ suggest that it too is single-phase.

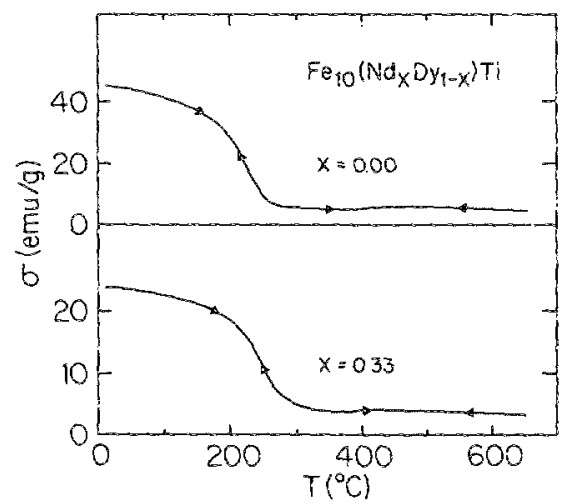

FIG. 3. Thermomagnetic data at $H=1.3 \mathrm{kOe}$ for $x=0.0$ and 0.33 .

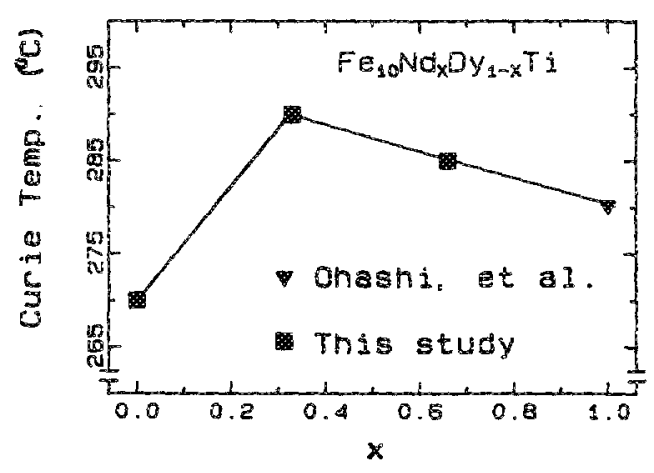

FIG. 4. Curie temperature vs composition for the $F e_{10} \mathrm{Nd}_{x} D y_{1-x}$ Ti series.

The bottom half of Fig. 1 shows diffraction data for the heat-treated sample with $x=0.33$. As indicated in the figure, the material contains a substantial amount of $\alpha-\mathrm{Fe}$. All of the heat-treated samples studied (including $x=0.0$ ) show this iron precipitation upon annealing.

The thermomagnetic data in Fig. 3 indicate the presence of a high-temperature magnetic phase above the Curie point of the tetragonal phase. The $\mathrm{x}$-ray data indicate that this secondary phase is $\alpha$-Fe.

Magnetization data at $H=8 \mathrm{kOe}$ for this series are summarized in Figs. 4 and 5. Figure 4 shows that the Curie temperature $T_{c}$ for the heat-treated samples rises from $270^{\circ} \mathrm{C}$ for $x=0.0$ to $290^{\circ} \mathrm{C}$ for $x=0.33$ and then diminishes with increasing $x$.

The hysteresis measurements for this series indicate that the largest room-temperature coercivity is $630 \mathrm{Oe}$ and occurs in samples with $x=0.0$. There was no significant difference between the hysteresis loops for as-quenched and heattreated samples. TEM measurements indicate that the typical grain size for the $x=0.0$ sample is about $4000 \AA$. This indicates that despite the rapid quenching, the grain size is so large that there is little magnetic hardening due to microstructure.

Measurements to $80 \mathrm{kOe}$ how that for $x=0.0$ the average moment per iron is about $1.8 \mu_{B}$, assuming the structure is ferrimagnetic, i.e., the Dy moment opposes the Fe moment. Similar results are found for $x=1.0$ assuming a ferromagnetic structure for the $\mathrm{Nd}$.

Table I summarizes the results of the magnetic measurements. These data indicate that $\mathrm{Fe}_{10} \mathrm{SmV}$ has the largest magnetization of the $\mathrm{Fe}_{10} \mathrm{SmM}$ materials studied. Hystere-

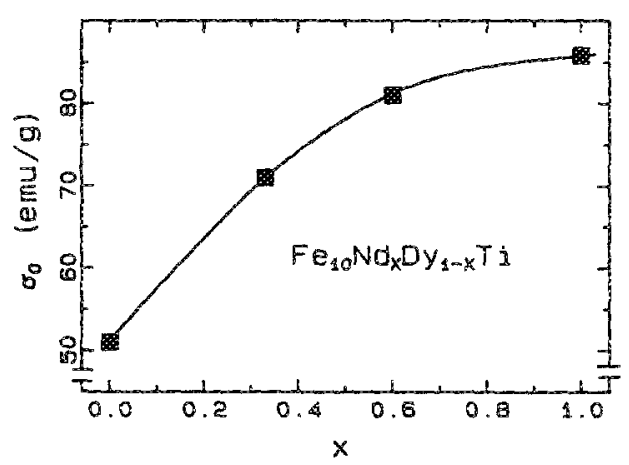

FIG. 5. Magnetization at $H=8 \quad \mathrm{kOe}$ ys composition for the $\mathrm{Fe}_{10} \mathrm{Nd}_{x} \mathrm{Dy} \mathrm{y}_{1 \ldots x} \mathrm{Ti}$ series. 
TABLE I. Magnetization at $8 \mathrm{kOe}$ for the $\mathrm{Fe}_{10} \mathrm{SmM}$ and $\mathrm{Fe}_{50} \mathrm{RV}$ series.

\begin{tabular}{lc}
\hline \hline Sample & $\sigma_{0}(\mathrm{emu} / \mathrm{g})$ \\
\hline$F \mathrm{e}_{10} \mathrm{SmV}$ & 98.6 \\
$\mathrm{Fe}_{10} \mathrm{YV}$ & 94.8 \\
$F \mathrm{e}_{10} \mathrm{SmTi}$ & 86.6 \\
$\mathrm{Fe}_{10} \mathrm{GdV}$ & 70.0 \\
$\mathrm{Fe}_{10} \mathrm{SmMO}$ & 68.3 \\
$\mathrm{Fe}_{10} \mathrm{DyV}$ & 64.2 \\
\hline
\end{tabular}

sis measurements show that $\mathrm{Fe}_{10} \mathrm{GdV}$ has the highest coercivity of all the samples studied, $1.2 \mathrm{kOe}$.

Preliminary $x$-ray data on the series indicate that the asquenched $F e_{10} S m M$ and $F e_{30} R V$ series are single phase. The precipitation of $\alpha-\mathrm{Fe}$ upon heat treatment has also been observed in these series.

\section{CONCLUSION}

This study indicates that rapidly quenched $\mathrm{Fe}_{10} \mathrm{RM}$ alloys have structures that are generally consistent with the
$\mathrm{ThMn}_{12}$ structure. However, some evidence has been obtained for a modulation of about $12 \AA$ along the $c$ axis, which requires further study. Annealing these samples at $800^{\circ} \mathrm{C}$ produced multiphased mixtures containing $\alpha-F e$. TEM measurements indicate that despite rapid quenching the alloys are rather coarse grained. This may explain the small coercivities observed for both as-quenched and annealed samples.

\section{ACKNOWLEDGMENTS}

We thank $J$. Steele for assistance in gathering data. For financial support we are indebted to the U.S. Department of Energy under Grants Nos. DE-FGO2-86ER45262 and DEFGO2-86ER45263.

'See K. H. J. Bushow, Mater. Sci. Rep. 1, 1 (1986), and references therein. ${ }^{2} \mathrm{~K}$. Ohashi, T. Yokogama, R. Osugi, and $\mathrm{Y}$. Tawara (unpubhished). 